\title{
The Transfer Problem in the Euro Area
}

\author{
Alessandro Girardi • Paolo Paesani
}

Published online: 24 July 2007

(C) Springer Science + Business Media, LLC 2007

\begin{abstract}
Building on the celebrated Keynes-Ohlin debate and on Lane and MilesiFerretti (Rev Econ Stat 86:841-857, 2004), the paper investigates the transfer problem for the Euro area vis-à-vis the rest of the world. The analysis is developed in a theoretically and statistically consistent way and is intended as a contribution to the empirical literature on EMU. The main result of the paper is that the accumulation of net foreign asset in the Euro area is consistent with real exchange appreciation, largely through the relative price of nontradables rather than through the terms of trade.
\end{abstract}

Keywords Transfer problem $\cdot$ Euro area $\cdot$ Cointegration

\section{JEL Classification $\mathrm{C} 32 \cdot \mathrm{C} 51 \cdot \mathrm{F} 21$}

The transfer problem was first mentioned in 1929, in the context of a celebrated debate between J. M. Keynes and B. Ohlin on how Germany should pay its war reparations. As Keynes recalled

"The Dawes Committee divided the problem of the payment of German reparations into two parts - into the budgetary problem of extracting the necessary sums of money out of the pockets of the German people (...) and the transfer problem of converting the German money so received into foreign currency" (Keynes (1929), p. 1).

\footnotetext{
A. Girardi

Department of Economics and Institutions, Institute for Economic Studies and Economic Analyses (ISAE), University of Rome "Tor Vergata", Rome, Italy

e-mail: a.girardi@isae.it

P. Paesani $(\bowtie)$

Department of Economics and Institutions, University of Rome "Tor Vergata", Via Columbia 2, 00133 Rome, Italy

e-mail: paolo.paesani@uniroma2.it
} 
The transfer problem, the problem of adjusting to international payments, has become one of the most hotly debated issues in the field of international macroeconomics. The purpose of this paper is to investigate the relevance of this issue for the Euro area vis-à-vis the rest of the (industrialized) world. The analysis is developed in a theoretically consistent way and improves upon previous contributions by making use of the Vector Error Correction (VEC) model. Our modeling strategy is particularly well suited to address both the long-run nature of the problem in a non-stationary environment and issues related to short-run adjustment. The rest of the paper is structured as follows. Section 1 reviews the literature on the transfer problem, Section 2 defines the theoretical and econometric framework of the analysis. Section 3 describes the data. Empirical results are discussed in Sections 4 and 5. Section 6 concludes.

\title{
1 The transfer problem, net foreign assets and the real exchange rate
}

The original point made by Keynes was that

"The solution of the transfer problem must come about (...) by the diversion of German factors of production from other employments into the export industry. (...) The transfer problem consists in reducing the gold-rate of efficiencyearnings of the German factors of production sufficiently to enable them to increase their exports to an adequate aggregate total.” (Keynes 1929, p. 3)

Ohlin (1929) responded by claiming that less (external) borrowing by Germany would imply a redistribution of purchasing power from Germany to the rest of the world, falling (rising) demand for home market goods in Germany (the rest of the world) and diversion of factors towards (away from) the export sector, even with constant or slightly depreciated terms of trade.

\begin{abstract}
'Mr. Keynes' (...) reasoning ignores, however, one important side of the problem. (...) A and B are two countries with normal employment for their factors of production. A borrows a large sum of money from B (...) The increased demand for home market goods in A will lead to an increased output of these goods. In a progressive country this means that labor and capital, that would otherwise have passed to export industries (...) now go to the home market instead. Thus there is a relative decline in A's (net) exports. A corresponding adjustment takes place in B. (...) Home market prices tend to rise in $\mathrm{A}$ and fall in $\mathrm{B}$, relative to prices of export and import goods (...). It is not necessary that A's export prices should rise and B's fall" (Ohlin 1929, p. 174). ${ }^{1}$
\end{abstract}

Both economists agreed that if a country persistently accumulates net foreign assets (liabilities), the implied wealth transfer, generated by the inflow (outflow) of

\footnotetext{
${ }^{1}$ Keynes retorted that "... In so far as Germany can (...) pay reparations without borrowing, these payments will react on the levels of income abroad. (...) But the increased buying power, due to the fact that Germany is paying something with less assistance than before from borrowing, will have been already used up in buying the exports the sale of which has made the reparations payment possible".
} 
interest and principal requires some degree of real exchange rate appreciation (depreciation) in the long-run. ${ }^{2}$

Building on this seminal intuition, many studies have been devoted to understanding the macroeconomics of net foreign assets ${ }^{3}$ and its relationship with the real exchange rate. In a Keynesian setting, countries with large net external liabilities need a depreciated real exchange rate to produce the large surpluses necessary for debt service. In intertemporal optimizing models, the transfer effect can operate in the presence of a home preference for domestic tradables, through the impact of wealth effects on labor supply, or through changing wages and production costs (Lane and Milesi-Ferretti 2004, and cited reference). Focusing on empirical results, Gagnon (1996) finds a direct relationship between the real exchange rate and net foreign assets (expressed as a fraction of trade flows) both in the short and the long-run for a panel of industrialized countries. Lane and Milesi-Ferretti (2004) find that, controlling for relative output levels and the terms of trade, a long-run relation exists between net foreign asset and the real exchange rate. The evidence also suggests that the relative price of traded to nontraded goods plays an important role in this longrun relation which tends to be inversely related to openness.

\section{Theoretical and econometric framework}

\subsection{Theoretical foundations}

The theoretical framework of this paper is provided by Lane and Milesi-Ferretti (2004). The model considers an open economy including a tradable and a nontradable sector. The output of the tradable sector is an endowment $Y_{T t}$ that sells on world markets at the export price $P_{T t}^{x}$, measured in units of the imported tradable consumption good. Assuming, for simplicity, that domestic consumption of the export good is zero, $P_{T t}^{x}$ is a measure of the terms of trade. Labor is supplied to the competitive sector where nontradables are produced (nontraded sector in what follows). The objective function of the representative agent $j$ is

$$
V_{j}=\sum_{t=0}^{\infty} \beta^{t} \cdot\left[\frac{\sigma}{\sigma-1} \cdot C_{t}^{\frac{\sigma-1}{\sigma}}-\frac{\kappa}{2} \cdot l_{N t}^{2}\right]
$$

\footnotetext{
${ }^{2}$ The transfer effect is by no means the only linkage between a country's real exchange rate and its net foreign assets. As Lane and Milesi-Ferretti (2001) point out, at a shorter horizon the interplay between the exchange rate and the trade balance is complex and less than well understood. In tracking net foreign assets/GDP dynamics, real exchange rates operate through the trade balance, the foreign currency value of domestic GDP (the so-called denominator effect) and the rates of return on foreign assets and liabilities (the so-called valuation effect). On the theoretical and empirical problems related to valuation effect see Gourinchas and Ray (2005).

${ }^{3}$ Net foreign assets are a key state variable in many open-economy models of growth and the business cycle. On this see Faruqee and Laxton (2000), Kraay and Ventura(2000), Lane and Milesi-Ferretti (2002), Bussiere et al. 2003, and Selaive and Tuesta (2003a, b).
} 
where $\beta \in(0,1)$ and $\sigma, \kappa>0$. The consumption index $C_{\mathrm{t}}$ aggregates consumption of traded (imported) and nontraded (home-made) goods according to the formula

$$
C_{t}=\left[\gamma^{\frac{1}{\theta}} \cdot C_{T t}^{\frac{\theta-1}{\theta}}+(1-\gamma)^{\frac{1}{\theta}} \cdot C_{N T t}^{\frac{\theta-1}{\theta}}\right]^{\frac{\theta}{\theta-1}}
$$

where $\theta$ is the elasticity of substitution between traded and nontraded goods. The second term in the objective function $V_{\mathrm{j}}$ captures the disutility of the work effort. The term $l_{\mathrm{Nt}}$ measures the amount of labor supplied to the nontraded sector where it is employed according to the linear production function $Y_{\mathrm{Nt}}=l_{\mathrm{Nt}}$, receiving the nominal wage $W_{\mathrm{t}}=P_{\mathrm{NTt}}$. The representative agent can use her savings to buy an international real bond $B$, denominated in units of the imported good and paying off the net real return $r$, according to the following flow budget constraint.

$$
B_{t+1}=(1+r) \cdot B_{t}+w_{t} \cdot l_{N t}+P_{T t}^{x} \cdot y_{t}-P_{t} \cdot C_{t}
$$

The consumption price index $P_{\mathrm{t}}$ is

$$
P_{t}=\left[\gamma+(1-\gamma) \cdot P_{N T t}^{1-\theta}\right]^{\frac{1}{1-\theta}}
$$

The real exchange rate RER is defined as the ratio of the domestic consumer price index to the foreign consumer price index $P_{t}^{*}$. This is held fixed throughout the analysis and normalized to unity, implying RER $=P_{\mathrm{t}}{ }^{4}$ After solving the representative agent's problem, under the assumption that $\beta \cdot(1+r)=1$ and linearly approximating the first-order conditions around the steady state, the steady state equation for the logarithm of the real exchange rate is

$$
\operatorname{rer}_{t}=\alpha+\beta_{1} \cdot n f a+\beta_{2} \cdot \operatorname{tra}+\beta_{3} \cdot \text { tot } ; \beta_{1}, \beta_{2}, \beta_{3}>0
$$

Equation 5 identifies the real exchange rate (rer) as a function of the net foreign asset/GDP ratio (nfa), the level of (tradable) output (tra) and the terms of trade (tot). Its interpretation is straightforward. Any factor allowing the representative agent to increase its consumption of (imported) tradables, be it net foreign asset accumulation, an increase in the level of exports, or an improvement in the terms of trade, has a positive wealth effect which reduces the labor supply to the nontradables sector leading to an increase in the relative price of nontradables and to real exchange appreciation. $^{5}$

\footnotetext{
${ }^{4}$ In this model the real exchange rate is mechanically independent of the terms of trade, since the only tradables which are consumed in the country are produced abroad and their price is held fixed. Movements in the terms of trade may influence the real exchange rate indirectly through a wealth effect on the relative price of nontradables. It may be objected that the terms of trade are endogenous for a large bloc of countries such as the Euro area - but this can be dismissed on the basis of the argument that exogenous oil prices drive the European terms of trade. We thank the anonymous referee for pointing this out.

${ }^{5}$ Available statistical sources make it difficult to obtain an exact counterpart of the variables required by the model. On the basis of this consideration, we have chosen to construct our time-series in the same way as Lane and Milesi-Ferretti (2004) do, maximize the compatibility between the theoretical framework and the empirical analysis.
} 


\subsection{Empirical implementation}

The possibility of net foreign assets reacting to changes in the real exchange rate is addressed by making use of a multi-equation vector error correction (VEC) model. VEC modeling builds on the association between the economic concept of long-run and the statistical concept of stationarity and focuses on the identification of stationary linear combinations of the data, known as cointegration vectors. These vectors describe the steady-state configuration which the model tends to revert to in the longrun once the effect of transitory shocks goes away. Cointegration vectors are identified on the basis of appropriate statistical tests. Considerable emphasis is usually placed on the idea that this identification should be theoretically consistent (Pagan 2003). Adopting the same notation as introduced above, the VEC model, forming the basis of our investigation, may be written as followsinvestigation, may be written as follows

$$
\left[\begin{array}{c}
\Delta r e r_{t} \\
\Delta n f a_{t} \\
\Delta t r a_{t} \\
\Delta t o t_{t}
\end{array}\right]=a+\sum_{j=1}^{p-1} \Gamma_{j} \cdot\left[\begin{array}{c}
\Delta r e r_{t-1} \\
\Delta n f a_{t-1} \\
\Delta t r a_{t-1} \\
\Delta t o t_{t-1}
\end{array}\right]+\Pi \cdot\left[\begin{array}{l}
r e r_{t-1} \\
n f a_{t-1} \\
t r a_{t-1} \\
\operatorname{tot}_{t-1}
\end{array}\right]+\Phi \cdot d_{t}+u_{t} \quad u_{t} \sim N\left(0, \sum u\right)
$$

Estimating Eq. 6 requires taking three-steps. First, unit root and stationarity tests are conducted on to investigate the order of integration of the system. Second, the lag length $p$ and the deterministic component $d_{\mathrm{t}}$ are chosen so that estimated residuals match the multi-normal distribution as closely as possible, this being an essential requirement for a correct statistical inference. Third, the long-term component of the model is identified.

The number of cointegration vectors is equal to the (reduced) rank of the matrix $\Pi$ and is determined on the basis of two tests: the trace test and the maximum eigenvalue test (Johansen 1995). Being of reduced rank, matrix $\prod$ can be partitioned as $\mathrm{A} \times \mathrm{B}^{\prime}$. Matrix $\mathrm{B}$ contains the $r<k$ cointegration vectors. Matrix A contains the feedback coefficients (loadings). Full theoretical consistency of the data, to be statistically tested, implies the following structure for the B space

$$
\left[\begin{array}{llll}
1 & -\beta_{1} & -\beta_{2} & -\beta_{3}
\end{array}\right] \cdot\left[\begin{array}{c}
r e r_{t-1} \\
n f a_{t-1} \\
t r a_{t-1} \\
t o t_{t-1}
\end{array}\right]=\left[\mu_{1}\right]
$$

Once the cointegration space is identified, the dynamics of the system are analyzed by discussing persistence profiles (Pesaran and Shin 1996) and generalized impulse response functions, GIRF (Pesaran and Shin 1998). Persistence profiles describe how the system returns to its steady-state after being perturbed by a shock affecting the system as a whole. GIRF show the effects of unit shocks on each cointegration relation (or on a specific variable), taking into account the residual correlation structure. GIRF analysis cannot be given a structural interpretation, but is a way to overcome the identification problem, while providing a significant characterization of dynamics of the system. 


\section{The data}

The empirical literature on EMU is hampered by the lack of long time-series. One way to side-step this problem consists in constructing synthetic time-series, obtained by aggregating the data of countries currently belonging to EMU as if EMU had existed before 1999. The use of synthetic time-series is open to many questions, ranging from the validity of the as if clause to what weights to use in the aggregating procedure. Recent contributions to the literature on EMU (e.g. Agresti and Mojon 2003; Peersman and Smets 2003; Mojon and Peersman 2003), however, confirm the validity of the aggregating expedient, encouraging us to take the same stand.

\subsection{Data sources and construction of the variables}

The data to construct the series are provided by the OECD (Main Economic Indicators, CD-ROM release 2005/2) and the IMF (IFS CD-Rom, February 2006), as Table 1 below indicates in detail.

The variables are: CPI-based real effective exchange rate (rer), relative level of (tradable) output (tra), terms of trade (tot) net foreign asset/GDP ratio (nfa). The dataset consists of 100 quarterly points observed between $1979 q 1$ and $2003 q 4$, covering the entire post-oil-shocks EMS-EMU period. ${ }^{6}$ Tables 2 and 3 explains how the variables were constructed, ${ }^{7}$ while Fig. 1 shows their pattern over the sample period.

The data graphs in Fig. 1 show that there seems to be an association between the trend in the aggregate NFA position of the Euro area and the trend in the real exchange rate. From the graphs, it also seems clear that the timing of terms of trade movements are such that the long-run co-movement between the terms of trade and the real exchange rate are low. ${ }^{8}$

Euro area data are calculated as weighted averages of single EMU countries data. ${ }^{9}$ The weights $w_{j}$ measure each country's real GDP (in PPP terms) over total Euro area real GDP (base year 1995). Rest of the world data are computed as weighted averages of Euro area main trading partners' data. ${ }^{10}$ The weights $w_{j}$ measure country's $i$ trade

\footnotetext{
${ }_{6}$ Troubles on the energy markets in 2004 and in 2005, whose effects might be particularly severe for oildependent economies such as the Euro area, suggest to limit our sample to 2003.

${ }^{7}$ While for rer and tra the rest of the world is limited to eight industrial countries outside the Euro area, for tot and nfa the rest of the world includes every country outside the Euro area. Despite its apparent inconsistency, our choice may be justified as follows. First, the eight economies considered as rest of the world for tot and nfa constitute around four-fifths of the external trade of the Euro area. Regional developments in Eastern Europe and Asia are not negligible but of secondary relevance. Second, our measure of rer is highly correlated with other "official" measures of CPI-based real effective exchange rate for the Euro area, as the one used in Fagan et al. (2005). Third, the construction of a world (per capita) output series requires an unavoidable approximation. Using the same aggregating procedure for rer and tra is intended to control that source of arbitrariness.

8 For the aggregate Euro area, the graph suggests that the terms of trade are driven by fluctuations in the oil price. See also Backus and Crucini (2000) on this point.

${ }^{9}$ Euro area includes: Austria. Belgium, Finland, France, Germany, Ireland, Italy, the Netherlands and Portugal.

${ }^{10}$ Rest of the world includes: Canada, Denmark, Japan, Norway, Sweden, Switzerland, the United Kingdom, the USA.
}

Springer 
Table 1 Data sources

\begin{tabular}{|c|c|c|c|}
\hline Series & Definition & Source & Code \\
\hline$R Y$ & Real GDP $(1995=100)$ & IFS February 06 & 99BVP/R...ZF \\
\hline$Y$ & Nominal GDP & IFS February 06 & 99B/C...ZF \\
\hline POP & Population & IFS February 06 & 99Z..ZF \\
\hline$P$ & Consumer price index & IFS February 06 & $64 \ldots \mathrm{ZF}$ \\
\hline$E$ & NC-US dollar nominal exchange rate & IFS February 06 & RF...ZF \\
\hline$U V E$ & Unit value of exports & IFS February 06 & 74..ZF \\
\hline$U V M$ & Unit value of imports & IFS February 06 & 75..ZF \\
\hline$F X R$ & Foreign exchange reserves & IFS February 06 & 1D.DZF \\
\hline$D I A$ & Direct investment abroad & IFS February 06 & 78...BDDZF \\
\hline$P I A$ & Portfolio investment assets & IFS February 06 & 78...BFDZF \\
\hline$O I A$ & Other investment assets & IFS February 06 & 78...BHDZF \\
\hline$D I L$ & Direct investment in rep. Economy & IFS February 06 & 78...BEDZF \\
\hline$P I L$ & Portfolio investment liabilities & IFS February 06 & $78 \ldots \mathrm{BGDZF}$ \\
\hline OIL & Other investment liabilities & IFS February 06 & 78...BIDZF \\
\hline$N F A^{79}$ & Stock of net foreign asset in 1979 & Lane and Milesi-Ferretti (2001) & ACUMCA \\
\hline
\end{tabular}

vis-à-vis the Euro area over total Euro area trade, defined as the sum of imports and exports and averaged over the period 1994-1996 (Lewbel 1992).

Net foreign assets are obtained by cumulating net foreign direct investment, net portfolio investment abroad, other net investment abroad and foreign exchange reserves, to the initial level of net foreign assets $(1979 q 1)$. This is the same methodology as employed by Lane and Milesi-Ferretti (2001) and Fagan et al. (2005). The relative level of output (tra) is calculated as the log-difference between the domestic (dpy) and foreign real GDP per-capita (fpy). The real exchange rate (rer) is computed as the log-difference between the (aggregate) Euro area nominal exchange rate vis-à-vis the rest of the world and the (aggregate) relative CPI index. ${ }^{11}$ Finally, the terms of trade index (tot) is calculated as the log-difference between the unit value of exports and imports between the Euro area and the rest of the world. ${ }^{12}$

\subsection{Unit root and stationarity tests}

As a preliminary exercise, we test for the presence of a unit root in each of the four series. ADF (Dickey and Fuller 1979) tests are performed on the series, both in levels and first differences, ${ }^{13}$ and are reported in the upper section of Table 4 . In each case, we are unable to reject the null hypothesis of a unit root at conventional levels of significance. On the other hand, differencing the series appears to induce stationarity. The KPSS (Kwiatkowski et al. 1992) stationarity tests, presented in the lower part of Table 4, corroborate these results.

\footnotetext{
${ }^{11}$ An increasing rer indicates real exchange rate appreciation.

12 The terms of trade reasonably approximate the relative price of domestic and foreign tradables only if the following two conditions are met: (1) exports (imports) are a large subset of domestic (foreign) tradables, reflecting the absence of trade barriers and taste differences; (2) producers do not price discriminate across markets.

13 The optimal lag for each test is determined on the basis of the Final Prediction criterion, with the maximum tested lag set equal to 10 . A constant term is included in each regression. Critical values for these tests are provided by Davidson and McKinnon (1993).
} 
Table 2 Construction of the variables

\begin{tabular}{ll}
\hline Variables & Definition \\
\hline Rer & $-\left[\sum_{j=1}^{10} w_{i} \cdot \ln \left(E_{j} / E_{j, 1995}\right)-\sum_{i=1}^{8} w_{i} \cdot \ln \left(E_{j} / E_{i, 1995}\right)+\sum_{i=1}^{8} w_{i} \cdot \ln \left(P_{i}\right)-\sum_{j=1}^{10} w_{j} \cdot \ln \left(P_{j}\right)\right]$ \\
Tot & $\sum_{j=1}^{10} w_{j} \cdot \ln \left[U V E_{j} / U V E_{j, 1995}\right]-\sum_{j=1}^{10} w_{j} \cdot \ln \left[U V M_{j} / U V M_{j, 1995}\right]$ \\
Dpy & $\sum_{j=1}^{10} w_{j} \cdot \ln \left[R Y_{j} /\left(P O P_{j} / P O P_{j, 1995}\right)\right]$ \\
Fpy & $\sum_{i=1}^{8} w_{i} \cdot \ln \left[R Y_{i} /\left(P O P_{i} / P O P_{i, 1995}\right)\right]$ \\
Nfa & $\sum_{j=1}^{10}\left(N F A_{j}^{79}+\sum D I A_{j}-D I L_{j}+P I A_{j}-P I L_{j}+O I A_{j}-O I L_{j}+F X R_{j}\right) / \sum_{j=1}^{10} Y_{j}$
\end{tabular}

Partner countries are reported in Table 3

\section{Empirical analysis: the benchmark case}

\subsection{Model specification}

The benchmark VEC model is estimated over the entire sample period, i.e. $1979 q 1-$ 2003q4. The lag-length is chosen according to the usual optimal lag criteria. As reported in Table 5 (lag determination), the Akaike information criterion (AIC) suggests choosing three lags, while the Bayesian information criterion (BIC) suggests

Table 3 Weights for aggregations

\begin{tabular}{lll}
\hline Countries & Weights & $w_{i}$ \\
\cline { 3 - 3 } & $w_{j}$ & \\
\hline Regional aggregation of the Euro area & & \\
AUT & 0.0303 & \\
BEL & 0.0338 & \\
FIN & 0.0170 & \\
FRA & 0.2101 & \\
GER & 0.3064 & 0.0242 \\
IRE & 0.0114 & 0.0542 \\
ITA & 0.2001 & 0.1094 \\
NET & 0.0576 & 0.0386 \\
POR & 0.0238 & 0.0787 \\
SPA & 0.1045 & 0.1227 \\
Euro area bilateral trade flow matrix & & 0.3348 \\
CAN & & 0.2374 \\
DEN & & \\
JAP & & \\
NOR & & \\
SWE & & \\
SWI & & \\
UK & & \\
USA & & \\
\hline
\end{tabular}

The weights are averages over the period 1994-1996. The weights sum to unit by column. Source: OECD Springer 
$n f a$

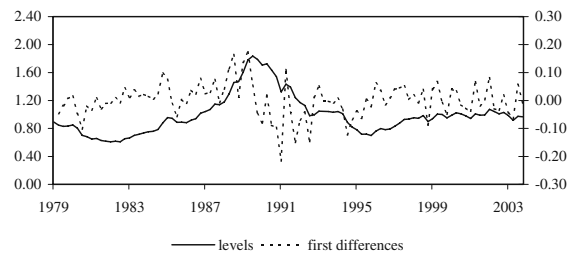

tot

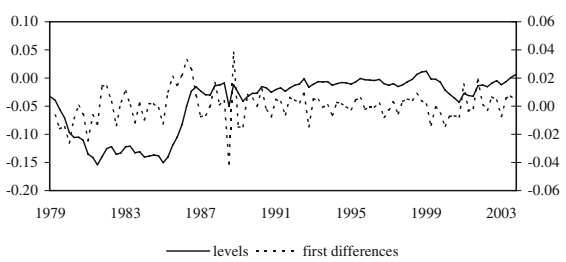

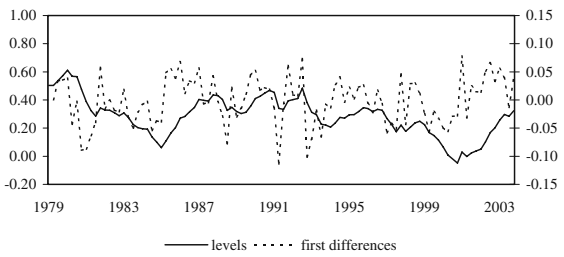

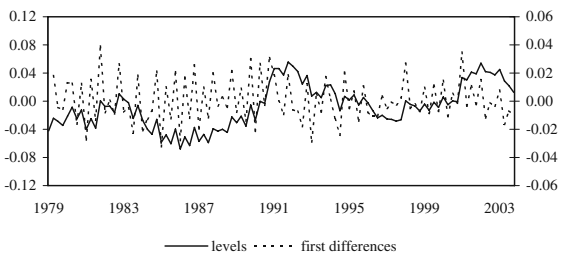

Fig. 1 The data: $1979 q 1-2003 q 4$

opting for two lags. Given the alternative, we prefer to allow for a richer system specification. System reduction tests $[\operatorname{LR}(p)$ and $\operatorname{LR}(p /$ pmax $)]$ support this choice.

The deterministic component includes a constant restricted to the cointegration space (cons), three centered seasonal dummies (the original data are not seasonally adjusted), one blip dummy (1988q3) to match an outlier, and four impulse dummies to account for the transition from EMS to $\operatorname{EMU~}(1999 q 4,2000 q 1,2000 q 3,2000 q 4) .{ }^{14}$ Misspecification tests (Table 6, misspecification tests) indicate that estimated residuals match the multi-normal distribution in a satisfactory way both at single equation and system level. Chow tests (available on request) indicate the presence of no residual instability in the model. Finally, the Trace and the Maximum eigenvalue cointegration tests (Table 7, rank determination) suggest choosing rank 1 for the $\Pi$ matrix, consistently with our a priori theoretical assumptions. ${ }^{15}$

\subsection{Modeling the long-run: structure of the $\prod$ matrix}

Lag determination in Table 8 contains the specification of the cointegration space, normalized on the real exchange rate coefficient. Standard errors suggest that the terms of trade and the constant term coefficient might be statistically not significant. Long-run exclusion tests confirm this suspicion. Testing separately the null

\footnotetext{
14 The impulse dummies were chosen on the basis of recursive 1-step-ahead Chow test and recursive cointegration tests. The idea of modeling the transition from one policy regime to another by means of a sequence of impulse dummies is proposed by Johansen et al. (2000).

15 As a robustness check, the PPI-based real exchange rate was tried out en lieu of the CPI-based real exchange rate (rer). Under this alternative specification, however, poor results were obtained. As to this, the CPI nontradable component is larger than its PPI counterpart. This makes PPI unsuitable to measure the kind of transmission from Net foreign assets to the real exchange rate as discussed by Ohlin. The argument whether the CPI or the PPI price level should be the most appropriate price index in the construction of the real exchange rate goes back to Keynes (1932). Nevertheless, it is worth noticing that the CPI-PPI distinction is a subtle one since the two price indices are highly correlated and differences in their movements are, in general, very difficult to explain. On this see Sarno and Taylor (2002).
} 
Table 4 Unit root and stationary tests: $1979 q 1-2003 q 4^{a}$

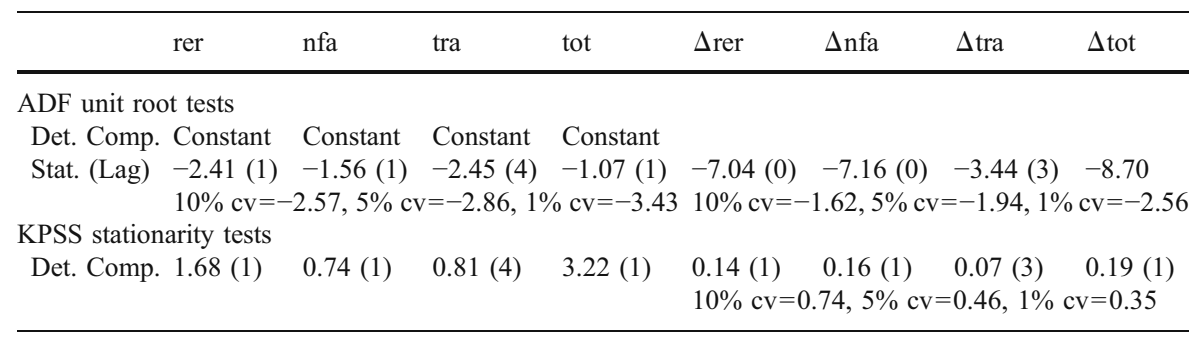

\begin{abstract}
${ }^{a}$ In the ADF tests, the order of autoregression, reported in parentheses, is chosen according to the BIC criterion. Critical values for the ADF and the KPSS tests at the 10, 5 and 1\% level of significance to two decimal places are reported in the lower part of each panel. Delta is the first difference operator
\end{abstract}

hypothesis of each coefficient being equal to zero against the alternative, we obtain the following result tot: $\chi^{2}(1)=0.01$ [0.92]; cons: $\chi^{2}(1)=0.05$ [0.82], nfa: $\chi^{2}(1)=8.15$ [0.00], tra: $\chi^{2}(1)=9.05$ [0.00]. Based on these findings, zero-restrictions are imposed on the coefficients of the terms of trade and the constant term. According to the corresponding LR test (Table 8, restricted cointegration vector), this restriction is strongly not rejected by the data $(p$ value $=0.98) .{ }^{16}$

The sign of the nfa coefficient is consistent with the presence of a significant Transfer effect, comparable to what Lane and Milesi-Ferretti (2004) find for a panel of industrialized economies, while the terms of trade coefficient turns to be not statistically significant. $^{17}$

Based on our preferred specification, which further restricts the model by imposing the long-run weak exogeneity of net foreign assets (Table 8, restricted long-run matrix), ${ }^{18}$ the following considerations are due. First, the model exhibits multiple paths of adjustment to the long-run. Second, the adjustment via $\Delta$ rer is consistent with our theoretical a priori and with the error correction mechanism. Third, the adjustment via $\Delta$ rer reflects the error correction mechanism. ${ }^{19}$ Fourth, the adjustment via $\Delta$ tot suggests an indirect influence on the real exchange rate on the relative price of non-tradables, consistent with theoretical a priori.

\footnotetext{
${ }^{16}$ On this see Lütkepohl and Krätzig (2004).

17 The fact that tra enters the vector with the opposite sign with respect to theoretical a priori might depend on the labor productivity ratio being a poor proxy for the levels of tradable output. Lane and MilesiFerretti (2004) themselves, using the same variable, find a negative or statistically not-significant tra coefficient in many of their regressions. An alternative measure of tradable output we thought of using could have been the sum of the contributions of the primary and secondary sector (net of constructions) to GDP. Cross-country consistent data of this kind, however, are typically only available at a semi-annual or annual frequency. If the time span of the analysis is not extended (something we chose not to do at present), the resulting loss of degrees of freedom might worsen the statistical accuracy of our results.

18 This means that it should be possible to specify a subset model conditioning on this variable, which acts as a common trend of the system.

${ }^{19}$ In the long-run, productivity differentials changes are offset by opposite movements in the dynamics of real exchange rate; in the short run, productivity differentials growth rates are affected by transitory deviations from the steady-state path.
} 
Table 5 Specification tests: lag determination (four variables model: 1979q1-2003q4)

\begin{tabular}{lllrrr}
\hline & $\operatorname{LR}(p)$ & $\operatorname{LR}\left(p / p_{\max }\right)$ & $\log -L$ & AIC & BIC \\
\hline$p=1$ & $F(16,208)[0.00]$ & $F(64,268)[0.00]$ & 954.5 & 902.5 & 835.8 \\
$p=2$ & $F(16,208)[0.04]$ & $F(48,263)[0.00]$ & 992.0 & 924.0 & 836.8 \\
$p=3$ & $F(16,208)[0.07]$ & $F(32,252)[0.06]$ & 1009.4 & 925.4 & 817.7 \\
$p=4$ & $F(16,208)[0.30]$ & $F(16,208)[0.30]$ & 1021.9 & 921.9 & 793.7 \\
\hline
\end{tabular}

Under the null hypothesis there are $r$ cointegration vectors against the alternative one of exactly (at most) $r+1$ cointegration vectors for the maximum eigenvalue (trace) test. The rank $r$ is selected as the first nonsignificant statistics, starting from $r=0$. $p$-values are reported in square brackets

\subsection{Time profile of the disequilibrium absorption}

Persistence profiles assess how long the system takes to revert to its steady state path, after being hit by a system-wide shock. Figure 2 presents the time profile of this disequilibrium adjustment. ${ }^{20}$

The convergence towards the steady-state follows a hump-shaped trajectory. ${ }^{21}$ The effects of the initial shock are amplified up to the second quarter, declining afterwards. The half-life of the deviation from the steady-state is close to six quarters and the absorption process comes to an end within the third year of the simulation. ${ }^{22}$ It might be useful to construct a numerical summary for the comparison of the speed of convergence between pairs of competing models. To do this, we calculate the deviation from the steady state $f$ at the simulation horizon $k$. Given a non-negative loss function $L$, we define the convergence loss (CL)

$$
C L\left(k^{*}\right)=\frac{1}{k^{*}} \cdot \sum_{k=0}^{k^{*}} L\left(f_{k}\right)
$$

where $k^{*}$ is a truncation lag such that $f_{\mathrm{k}} \approx 0$. Natural symmetric loss functions are the absolute loss and the squared loss. Once the CL is computed, the comparison can be performed by means a standard two-sided $t$ test. In the case of the tetra-variate system estimated over the full sample, the CL obtained from an absolute loss turns to be equal to 0.31 .

GIRF analysis disentangles the effects exerted by shocks to each equation on the cointegration relationships. Three reasons motivate resorting to GIRF analysis. First, the

\footnotetext{
${ }^{20}$ The size of all the shocks analyzed in this section is set equal to one standard deviation.

${ }^{21}$ The simulation spans 20 quarters. Bootstrapped 95\% confidence intervals with 2,500 replications indicate that the responses of the cointegration vector to impulses on the nfa, tra and rer equations are statistically significant up the second year of the simulation. Conversely, the deviations from the baseline path induced by a shock on the tot equation are statistically negligible. These results are robust with respect to both the specification of the model (four and three variable cases) and the estimation horizon (1979-2003 and 1979-1998 samples). On the scant reliability of the confidence bounds for impulse response functions as indicator of the precision of estimates even at short and medium horizons, see Benkwitz et al. (2000).

${ }^{22}$ Half-life is defined as the number of quarters which have to pass before the deviation from the steadystate falls to half the size of the initial shock.
} 
Table 6 Specification tests: misspecification tests (four variables model: 1979q1-2003q4)

\begin{tabular}{lllll}
\hline & rer & nfa & tra & tot \\
\hline $\operatorname{AR}_{(1-5)} F(5,71)$ & {$[0.80]$} & {$[0.22]$} & {$[0.34]$} & {$[0.09]$} \\
${\text { Normality } \chi^{2}(2)}_{\mathrm{ARCH}_{(1-4)} F(4,68)}$ & {$[0.96]$} & {$[0.12]$} & {$[0.24]$} & {$[0.94]$} \\
Hetero $F(24,51)$ & {$[0.50]$} & {$[0.11]$} & {$[0.52]$} & {$[0.06]$} \\
Vector $\mathrm{AR}_{(1-5)} F(80,211)[0.06]$ & {$[0.78]$} & {$[0.30]$} & {$[0.05]$} & {$[0.34]$} \\
Vector normality $\chi^{2}(8)[0.07]$ & & & \\
Vector hetero $F(240,413)[0.95]$ & & & \\
\hline
\end{tabular}

Under the null hypothesis there are $r$ cointegration vectors against the alternative one of exactly (at most) $r+1$ cointegration vectors for the maximum eigenvalue (trace) test. The rank $r$ is selected as the first nonsignificant statistics, starting from $r=0 . p$-values are reported in square brackets

effects of shocks to the variables in a VEC model are not absorbed over time, but persist indefinitely because of the rank deficiency of the long-run $\Pi$ matrix. Deviations from the cointegration vectors due to shocks to the variables are, on the contrary, bound to be temporary "by construction". Second, even though GIRF analysis is based on the reduced form representation of the VEC model (i.e. shocks may be contemporaneously correlated), it is robust to permutations in the ordering of the variables. Third, GIRF circumvent many of the problems associated to uniquely determining structural disturbances.

Figure 3 shows how the cointegration vector responds to one-standard error shocks hitting each of the variables of the system. According to the figure, the time it takes to bring the system back to its equilibrium path is due to the persistent effects of shock to nfa, rer and tra, while shocks to the terms of trade tot produce a much smaller deviation both in terms of timing and magnitude. This is in line with the idea that protracted misalignments of the real exchange rate from its long-run level should be linked to fluctuations in the relative price of nontradables. The sign of the responses reflects that of the long-run coefficients in the equilibrium condition.

\section{Empirical analysis: extensions}

\subsection{The transfer problem and the price of nontradables}

Even though many Euro area members are small open economies, the Euro Area as a whole may be considered as a large and relatively closed economy. Based on this

Table 7 Specification tests: rank determination (four variables model: 1979q1-2003q4)

\begin{tabular}{|c|c|c|c|c|c|}
\hline \multirow{2}{*}{$\begin{array}{l}\text { Eigenvalues } \\
0.27\end{array}$} & \multirow{2}{*}{$\frac{\text { Rank }}{0}$} & \multicolumn{2}{|c|}{ Trace test } & \multicolumn{2}{|c|}{ Max eigenvalue test } \\
\hline & & 53.44 & {$[0.056]$} & 30.66 & {$[0.023]$} \\
\hline 0.11 & 1 & 22.77 & {$[0.547]$} & 11.09 & {$[0.742]$} \\
\hline 0.08 & 2 & 11.68 & {$[0.486]$} & 8.41 & {$[0.511]$} \\
\hline 0.03 & 3 & 3.27 & {$[0.541]$} & 3.27 & {$[0.540]$} \\
\hline
\end{tabular}

Under the null hypothesis there are $r$ cointegration vectors against the alternative one of exactly (at most) $r+1$ cointegration vectors for the maximum eigenvalue (trace) test. The rank $r$ is selected as the first nonsignificant statistics, starting from $r=0$. $p$-values are reported in square brackets 
Table 8 Long-run structure (four variables model: 1979q1-2003q4)

\begin{tabular}{|c|c|c|c|c|c|}
\hline & rer & $n f a$ & tra & tot & cons \\
\hline \multicolumn{6}{|c|}{ Unrestricted long-run matrix } \\
\hline Long-run relationship & 1 & $\begin{array}{l}-0.3130 \\
(0.0971)\end{array}$ & $\begin{array}{l}3.8991 \\
(1.0136)\end{array}$ & $\begin{array}{l}0.0553 \\
(0.5686)\end{array}$ & $\begin{array}{l}0.0276 \\
(0.1114)\end{array}$ \\
\hline Loading coefficients & $\begin{array}{l}-0.0856 \\
(0.0331)\end{array}$ & $\begin{array}{l}0.0335 \\
(0.0508)\end{array}$ & $\begin{array}{l}-0.0330 \\
(0.0097)\end{array}$ & $\begin{array}{r}-0.0282 \\
(0.0081)\end{array}$ & . \\
\hline \multicolumn{6}{|c|}{ Restricted cointegration vector $\chi^{2}(2)=0.05[0.98]$} \\
\hline Long-run relationship & 1 & $\begin{array}{c}-0.2881 \\
(0.0219)\end{array}$ & $\begin{array}{l}3.8594 \\
(0.8639)\end{array}$ & . & . \\
\hline Loading coefficients & $\begin{array}{l}-0.0871 \\
(0.0336)\end{array}$ & $\begin{array}{l}0.0298 \\
(0.0515)\end{array}$ & $\begin{array}{l}-0.0332 \\
(0.0098)\end{array}$ & $\begin{array}{l}-0.0290 \\
(0.0082)\end{array}$ & . \\
\hline \multicolumn{6}{|c|}{ Restricted long-run matrix $\chi^{2}(3)=0.44[0.93]$} \\
\hline Long-run relationship & 1 & $\begin{array}{c}-0.2871 \\
(0.0223)\end{array}$ & $\begin{array}{l}4.0483 \\
(0.8797)\end{array}$ & . & . \\
\hline Loading coefficients & $\begin{array}{l}-0.0728 \\
(0.0270)\end{array}$ & . & $\begin{array}{l}-0.0336 \\
(0.0097)\end{array}$ & $\begin{array}{l}-0.0277 \\
(0.0079)\end{array}$ & . \\
\hline
\end{tabular}

Standard errors are reported in parentheses. $p$-values of LR tests are reported in square brackets

argument, Euro area CPI-based real exchange rate fluctuations should reflect changes in the nontradable component of the price index, with the tradable component playing a lesser role. This conjecture is formally tested by constructing a new "dependent" variable, ntr, defined as the ratio between the CPI-based real exchange rate and the terms of trade, or equivalently as (rer-tot) in logarithm terms. Tables 9, 10, 11, and 12 summarizes estimation results for the tri-variate VEC model whose deterministic structure coincides with that of the tetra-variate system.

As reported in the lag determination, Table 9, system reduction tests and the BIC criterion suggest choosing three lags, while AIC suggests choosing four lags. For the sake of symmetry and comparability we chose $p=3 .^{23}$ Misspecification tests are satisfactory both at single equation and system level, even though evidence of nonnormality emerges from the vector test (Table 10, misspecification test). The rank of $\Pi$ is tested to be equal to 1 at the $5 \%$ significance level (Table 11, rank determination). Both the long-run coefficient on cons and the loading matrix coefficient on nfa can be set equal to zero mirroring the benxchmark specification. The null hypothesis is not rejected by the data with a $p$ value equal to 0.19 . The magnitudes of the (residual) long-run and loading matrix coefficients are very similar to those discussed in the previous section. Figure 4 compares persistence profiles for the two models, showing remarkable similarities.

The adjustment is hump-shaped in both cases, exhibiting the same speed of convergence in terms of half-life (six quarters). The initial phase of amplification of the shock lasts around two quarters. Even though a vigorous adjustment occurs afterward, the initial response of the system prolongs the adjustment process roughly by one year with non-monotonic mean-reversion in the real exchange mimicking the

\footnotetext{
$\overline{{ }^{23} \text { Results (available on request) }}$ are substantially unchanged with $p=4$.
} 


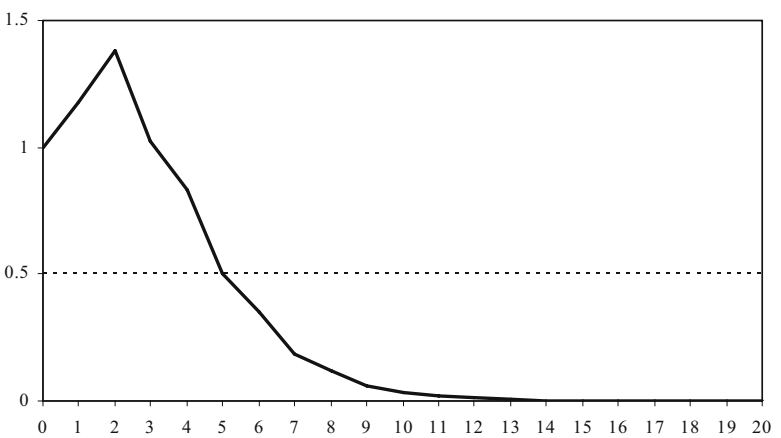

Fig. 2 Persistence profile. Four variables model: 1979q1-2003q4. The vertical axis indicates the magnitude of the deviation (normalized to unity on impact) from the steady-state level. The horizontal axis measures quarters after the shock. The horizontal line denotes half of the initial impact of the response

behaviour of the nontradable component of the CPI index. Finally, the CL is 0.32 and the $t$ test indicates not rejecting the null hypothesis of equivalence ( $p$ value equal to 0.98 ). This suggests that the Transfer effect works largely through the relative price of nontradables, consistently with the large and relatively closed-economy nature of the Euro area and with Ohlin (1929) conclusions.

GIRF analysis for the tri-variate model confirms previous results (Fig. 5). The effects of the shocks die out over time, validating the stationarity of the estimated long-run equilibrium condition. Moreover, the impulse responses match very closely their counterparts in Fig. 3.

\subsection{Assessing the role of EMU}

This section asks whether and to what extent the transition of from EMS to EMU has affected the transfer problem. So far this transition has been modeled by means of a sequence of deterministic dummies as in Johansen et al. (2000). Using dummies leads to the exclusion of the corresponding data from the estimation of the cointegration space. ${ }^{24}$ In what follows a different approach is adopted, to test the possible impact of EMU on the net foreign assets/real exchange rate relationship. A new model is estimated over the pre-EMU period only (1979q1-1998q4), comparing it both with the tetra-variate and tri-variate systems estimated over the entire sample period. Tables 13, 14, and 15 summarizes misspecification tests for the baseline tetra-variate model [rer, nfa, tot, tra]'. Residuals diagnostic tests results are satisfactory both at the single equation and system level (misspecification tests). The Trace test points to the presence of one cointegration relationship, at the $10 \%$ significance level (rank determination). The same over-identified cointegration structure is found to be adequate when estimating the long-run component of the model over the pre-EMU sub-sample only. The correlation coefficient between the

\footnotetext{
${ }^{24}$ For an example of cointegration analysis coupled with the exclusion of some observations to take account of a policy-regime change see Juselius (2003). 


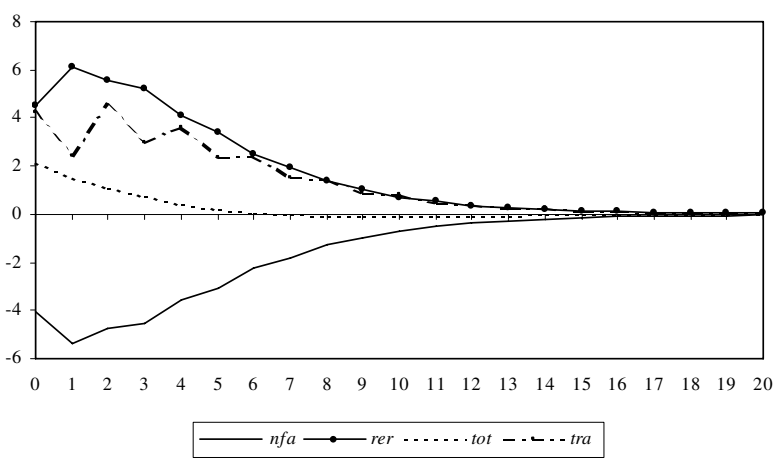

Fig. 3 Impulse response. Four variables model: 1979q1-2003q4. The vertical axis indicates the magnitude of the deviation (in percentage values) from the steady-state level (horizontal axis). Horizontal axis denotes quarters after the shock

Table 9 Three variables model, lag determination: 1979q1-2003q4

\begin{tabular}{lllllr}
\hline & $\operatorname{LR}(p)$ & $\operatorname{LR}\left(p / p_{\max }\right)$ & $\log -L$ & AIC & BIC \\
\hline$p=1$ & $F(9,177)[0.00]$ & $F(36,216)[0.00]$ & 250.3 & 223.3 & 188.6 \\
$p=2$ & $F(9,177)[0.00]$ & $F(27,213)[0.00]$ & 637.3 & 601.3 & 554.9 \\
$p=3$ & $F(9,177)[0.01]$ & $F(18,206)[0.02]$ & 664.4 & 619.4 & 561.5 \\
$p=4$ & $F(9,177)[0.30]$ & $F(9,177)[0.30]$ & 677.7 & 623.7 & 554.2 \\
\hline
\end{tabular}

Standard errors are reported in parentheses. $p$-values of LR tests are reported in square brackets

Table 10 Three variables model, misspecification tests: 1979q1-2003q4

\begin{tabular}{lllr}
\hline & $n t r$ & $n f a$ & tra \\
\hline $\mathrm{AR}_{(1-5)} F(5,74)$ & {$[0.67]$} & {$[0.36]$} & {$[0.10]$} \\
${\text { Normality } \chi^{2}(2)}_{\mathrm{ARCH}_{(1-4)} F(4,71)}$ & {$[0.91]$} & {$[0.09]$} & {$[0.08]$} \\
$\mathrm{Hetero} F(18,60)$ & {$[0.52]$} & {$[0.01]$} & {$[0.32]$} \\
Vector $\mathrm{AR}_{(1-5)} F(80,211)[0.26]$ & {$[0.79]$} & {$[0.04]$} & {$[0.24]$} \\
Vector normality $\chi^{2}(8)[0.00]$ & & & \\
Vector hetero $F(240,413)[0.59]$ & & &
\end{tabular}

Standard errors are reported in parentheses. $p$-values of LR tests are reported in square brackets 
Table 11 Three variables model, rank determination: 1979q1-2003q4

\begin{tabular}{|c|c|c|c|c|c|}
\hline \multirow{2}{*}{$\begin{array}{l}\text { Eigenvalues } \\
0.21\end{array}$} & \multirow{2}{*}{$\frac{\text { Rank }}{0}$} & \multicolumn{2}{|c|}{ Trace test } & \multicolumn{2}{|c|}{ Max eigenvalue test } \\
\hline & & 38.08 & [0.022] & 22.75 & {$[0.041]$} \\
\hline 0.08 & 1 & 15.33 & {$[0.213]$} & 8.39 & {$[0.514]$} \\
\hline 0.07 & 2 & 6.94 & {$[0.133]$} & 6.94 & {$[0.133]$} \\
\hline
\end{tabular}

Standard errors are reported in parentheses. $p$-values of LR tests are reported in square brackets

Table 12 Three variables model, restricted long-run matrix: 1979q1-2003q4

\begin{tabular}{lllll}
\hline & $n t r$ & $n f a$ & tra & cons \\
\hline Long-run relationship & 1 & $-0.3006(0.0341)$ & $4.5270(1.2787)$ &. \\
Loading coefficients & $-0.0501(0.0202)$ & $\cdot$ & $-0.0241(0.0080)$ & $\cdot$ \\
$\chi^{2}(2)=3.28[0.19]$ & & & & \\
\hline
\end{tabular}

Standard errors are reported in parentheses. $p$-values of LR tests are reported in square brackets

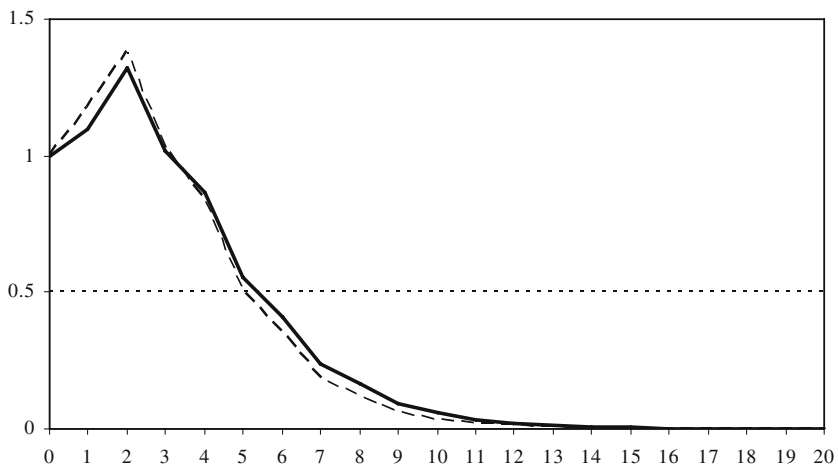

Fig. 4 Persistence profile. Three variables model: 1979q1-2003q4. Solid (dashed) line refers to the three (four) variable model. The vertical axis indicates the magnitude of the deviation (normalized to unity on impact) from the steady-state level (horizontal axis). Horizontal axis denotes quarters after the shock. Horizontal line: half of the initial impact of the response

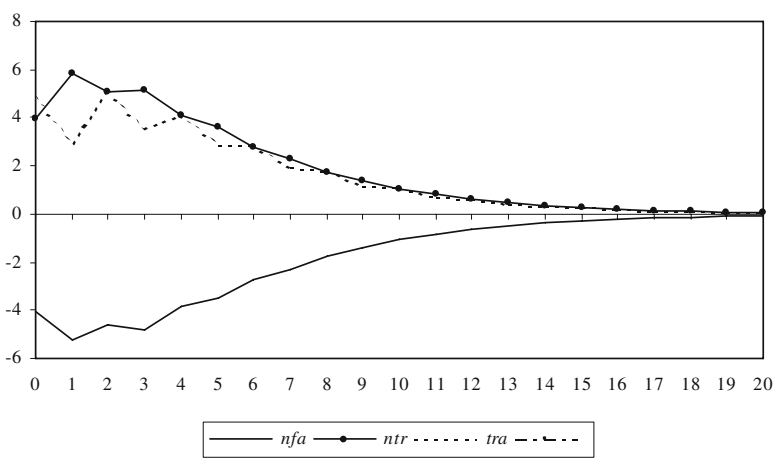

Fig. 5 Impulse response. Three variables model: 1979q1-2003q4. The vertical axis indicates the magnitude of the deviation (in percentage values) from the steady-state level (horizontal axis). Horizontal axis denotes quarters after the shock 
Table 13 Four variables model, misspecification tests: 1979q1-1998q4

\begin{tabular}{lllll}
\hline & rer & nfa & tra & tot \\
\hline $\mathrm{AR}_{(1-5)} F(5,55)$ & {$[0.51]$} & {$[0.35]$} & {$[0.75]$} & {$[0.25]$} \\
${\text { Normality } \chi^{2}(2)}$ & {$[0.69]$} & {$[0.08]$} & {$[0.22]$} & {$[0.75]$} \\
$\mathrm{ARCH}_{(1-4)} F(4,52)$ & {$[0.87]$} & {$[0.08]$} & {$[0.61]$} & {$[0.33]$} \\
Hetero $F(24,35)$ & {$[0.59]$} & {$[0.26]$} & {$[0.28]$} & {$[0.47]$} \\
Vector $\mathrm{AR}_{(1-5)} F(80,211)[0.21]$ & & & & \\
Vector normality $\chi^{2}(8)[0.19]$ & & & & \\
Vector hetero $F(240,413)[0.97]$ & & & & \\
\hline
\end{tabular}

Standard errors are reported in parentheses. $p$-values of LR tests are reported in square brackets

Table 14 Four variables model, rank determination: 1979q1-1998q4

\begin{tabular}{llcccc}
\hline Eigenvalues & Rank & Trace test & & \multicolumn{2}{c}{ Max eigenvalue test } \\
\hline 0.25 & 0 & 50.52 & {$[0.100]$} & 21.83 & {$[0.297]$} \\
0.19 & 1 & 28.69 & {$[0.214]$} & 16.62 & {$[0.266]$} \\
0.11 & 2 & 12.07 & {$[0.451]$} & 8.74 & {$[0.474]$} \\
0.04 & 3 & 3.33 & {$[0.531]$} & 3.33 & {$[0.530]$} \\
\hline
\end{tabular}

Standard errors are reported in parentheses. $p$-values of LR tests are reported in square brackets

Table 15 Four variables model, restricted long-run matrix: 1979q1-1998q4

\begin{tabular}{llllll}
\hline & rer & $n f a$ & tra & tot & cons \\
\hline Long-run relationship & 1 & $-0.2600(0.0322)$ & $4.3704(1.3006)$ &. &. \\
Loading coefficients & $-0.0783(0.0283)$ &. & $-0.0209(0.0104)$ & $-0.0269(0.0085)$ &. \\
$\chi^{2}(3)=2.92[0.40]$ & & & & & \\
\hline
\end{tabular}

Standard errors are reported in parentheses. $p$-values of LR tests are reported in square brackets

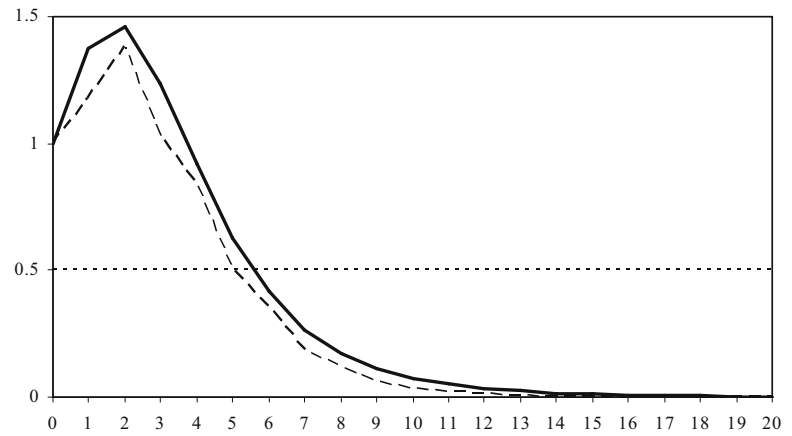

Fig. 6 Persistence profile. Four variables model: 1979q1-1998q4. Solid (dashed) line refers to the four variable model estimated over the period 1979q1-1998q4 (1979q1-2003q4). The vertical axis indicates the magnitude of the deviation (normalized to unity on impact) from the steady-state level (horizontal axis). Horizontal axis denotes quarters after the shock. Horizontal line: half of the initial impact of the response 


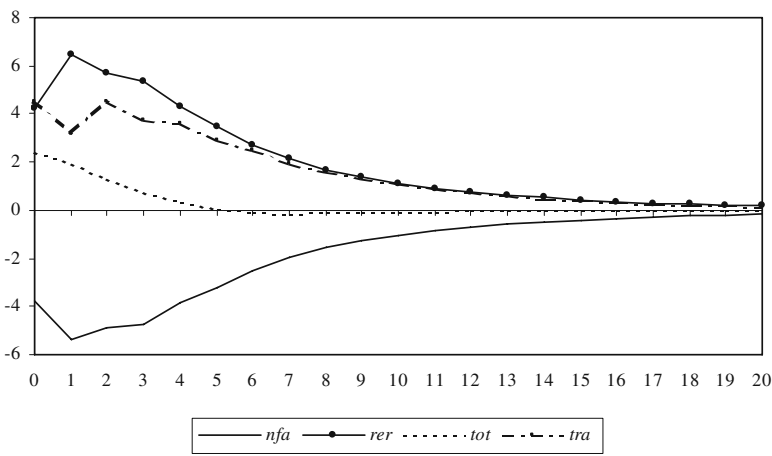

Fig. 7 Impulse response. Four variables model: 1979q1-1998q4. The vertical axis indicates the magnitude of the deviation (in percentage values) from the steady-state level (horizontal axis). Horizontal axis denotes quarters after the shock

cointegration residual over the full sample and the pre-EMU period estimates is very high (0.96) and statistically significant at the $1 \%$ level.

Based on these findings, the long-term linkage between net foreign assets and the real exchange rate appear not to have changed radically with the start of EMU. Persistence profile and GIRF analysis uphold this statement. As Figs. 6 and 7 indicate, not only the long-run properties of the model but also its short-run dynamics seem to be unchanged when comparing the two sample spans. The halflife of the Persistence profile is still six quarters. Furthermore, the equivalence test for the CLs produces a statistics equal to $(-0.40)$ with a $p$-value of 0.69 . Finally, impulse responses on the cointegration relationship tell the same story as Fig. 3.

The final step of the analysis consists in replicating the same comparing procedure on the tri-variate model [ntr, nfa, tra]'. Tables 16, 17, and 18 shows an adequate model specification with the long-run equilibrium condition supporting our preferred over-identified structure $(p$ value $=0.14)$.

The equilibrium absorption mechanism is consistent with the adjustment paths depicted in Figs. 4 and 5, even though pre-EMU years speed of convergence toward the steady-state (seven quarters) turns to be slightly lower $(\mathrm{CL}=0.37)$ than the full sample case even though no statistical differences emerge, with the $p$ value of the $t$ test equals to 0.70 (Figures 8 and 9).

Table 16 Three variables model, misspecification tests: 1979q1-1998q4

\begin{tabular}{llll}
\hline & $n t r$ & $n f a$ & tra \\
\hline $\mathrm{AR}_{(1-5)} F(5,54)$ & {$[0.51]$} & {$[0.60]$} & {$[0.66]$} \\
${\text { Normality } \chi^{2}(2)}_{\mathrm{ARCH}_{(1-4)} F(4,51)}$ & {$[0.80]$} & {$[0.04]$} & {$[0.18]$} \\
Hetero $F(18,40)^{\text {Vector } \mathrm{AR}_{(1-5)} \mathrm{F}(80,211)[0.28]}$ & {$[0.84]$} & {$[0.09]$} & {$[0.33]$} \\
Vector normality $\chi^{2}(8)[0.02]$ & & {$[0.11]$} & \\
Vector hetero $F(240,413)[0.85]$ & & & \\
\hline
\end{tabular}

Standard errors are reported in parentheses. $p$-values of LR tests are reported in square brackets 
Table 17 Three variables model, rank determination: 1979q1-1998q4

\begin{tabular}{|c|c|c|c|c|c|}
\hline \multirow{2}{*}{$\begin{array}{l}\text { Eigenvalues } \\
0.20\end{array}$} & \multirow{2}{*}{$\begin{array}{l}\text { Rank } \\
0\end{array}$} & \multicolumn{2}{|c|}{ Trace test } & \multicolumn{2}{|c|}{ Max eigenvalue test } \\
\hline & & 34.54 & {$[0.057]$} & 17.12 & {$[0.235]$} \\
\hline 0.14 & 1 & 17.42 & {$[0.118]$} & 11.92 & [0.197] \\
\hline 0.07 & 2 & 5.50 & [0.242] & 5.50 & [0.241] \\
\hline
\end{tabular}

Standard errors are reported in parentheses. $p$-values of LR tests are reported in square brackets

Table 18 Three variables model, restricted long-run matrix: 1979q1-1998q4

\begin{tabular}{lllll}
\hline & $n t r$ & $n f a$ & tra & cons \\
\hline Long-run relationship & 1 & $-0.2490(0.0508)$ & $5.9957(2.0345)$ &. \\
Loading coefficients & $-0.0579(0.0215)$ & $\cdot$ & $-0.0132(0.0083)$ &. \\
$\chi^{2}(2)=3.89[0.14]$ & & & & \\
\hline
\end{tabular}

Standard errors are reported in parentheses. $p$-values of LR tests are reported in square brackets

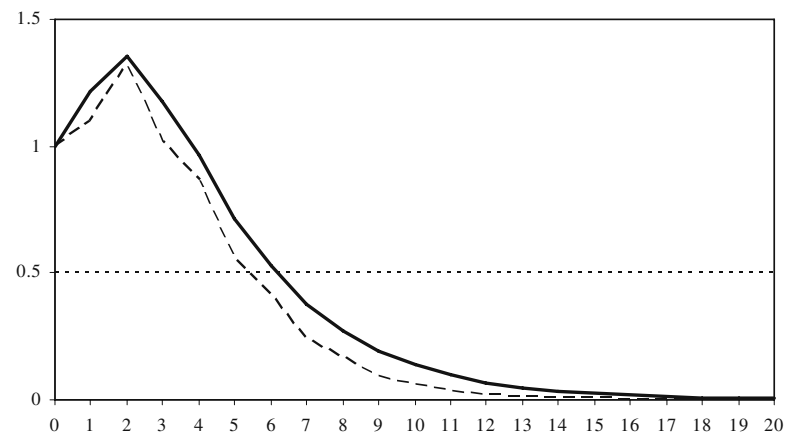

Fig. 8 Persistence profile. Three variables model: 1979q1-1998q4. Solid (dashed) line refers to the three variable model estimated over the period 1979q1-1998q4 (1979q1-2003q4). The vertical axis indicates the magnitude of the deviation (normalized to unity on impact) from the steady-state level (horizontal axis). Horizontal axis denotes quarters after the shock. Horizontal line: half of the initial impact of the response

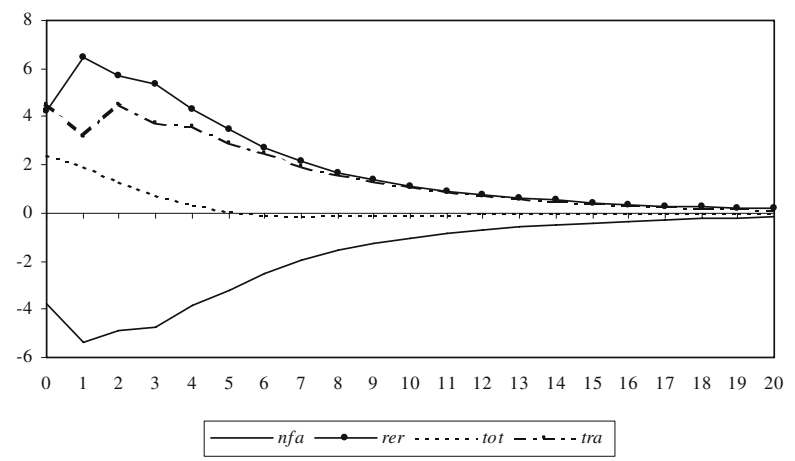

Fig. 9 Impulse response. Three variables model: 1979q1-1998q4. The vertical axis indicates the magnitude of the deviation (in percentage values) from the steady-state level (horizontal axis). Horizontal axis denotes quarters after the shock 


\section{Conclusions}

This paper empirically investigates the transfer problem for Euro area vis-à-vis the rest of the (industrialized) world in a statistically consistent way. The paper reaches three main conclusions.

First, as generally envisaged both by Keynes and Ohlin, net foreign asset (liabilities) accumulation is consistent with real exchange appreciation (depreciation) for the Euro area vis-à-vis the rest of the world. Second, as pointed out by Ohlin only, the transfer effect appears to work through the relative price of nontradables rather than through the terms of trade. Third, the transition from EMS to EMU appears to have had a statistically significant impact on the Transfer effect, of a transitory rather than permanent nature. The possibility of improving upon the aggregating procedure, e.g. taking valuation effects into account at quarterly frequencies, and of the analysis of other adjustment effects including those affecting relative labor productivity and the real exchange rate constitute possible extensions of the current research.

Acknowledgment The authors are grateful to the editor (George Tavlas), an anonymous referee, Gustavo Piga and Michele Bagella for helpful comments and suggestions on previous versions of the paper. The usual disclaimers apply. The views expressed do not necessarily reflect those of the Institute for Studies and Economic Analyses (ISAE).

\section{References}

Agresti A-M, Mojon B (2003) Some stylised facts on the Euro area business cycle. In: Angeloni I et al (Eds.) Monetary transmission in the Euro Area, Chapter 1. Cambridge University Press, Cambridge

Backus DK, Crucini MJ (2000) Oil prices and the terms of trade. J Int Econ 50:185-213

Benkwitz, A, Lütkepohl H, Neumann MH (2000) Problems related to confidence intervals for impulse of autoregressive processes. Econom Rev 19:69-103

Bussiere M, Choartareas G, Driver R (2003) Current accounts net foreign assets and the implications of cyclical factors. East Econ J 29:269-86

Davidson R, McKinnon JJ (1993) Estimation and Inference in Econometrics. Oxford University Press, Oxford

Dickey, DA, Fuller WA (1979) Distribution of the estimators for autoregressive time series with a unit root. J Am Stat Assoc 74:427-431

Fagan G, Henry JJ, Mestre R (2005) An area-wide model (AWM) for the Euro area. Econ model 22:39-59

Faruqee H, Laxton D (2000) Life cycle dynasties saving: implications for small open economies, International Monetary Fund, Working paper, 126

Gagnon JE (1996) Net foreign assets and equilibrium exchange rates: panel evidence, Board of Governors of the Federal Reserve System, International Finance discussion paper, 574

Gourinchas P-O, Ray H (2005) International financial adjustment, Centre for Economic Policy Research discussion paper, 4923

Johansen S (1995) Likelihood-based inference in cointegrated vector autoregressive models. Oxford University Press, Oxford

Johansen S, Mosconi R, Nielsen B (2000) Cointegration analysis in the presence of structural breaks in the deterministic trend. Econom J 3:216-249

Juselius K (2003) Wage, price, and unemployment dynamics and the convergence to purchasing power parity in the Euro Area. http://www.econ.ku.dk/okokj/Papers/Eurowideecb.pdf

Keynes J-M (1929) The german transfer problem. Econ J XXXIX:1-7

Keynes, J-M (1932) Essays in persuasion. Harcourt Brace Jovanovich, Orlando, FL

Kraay A, Ventura J (2000) Current accounts in debtor and creditor countries. Q J Econ 115:1137-1166

Springer 
Kwiatkowski D, Phillips PCB, Schmidt P, Shin Y (1992) Testing the null hypothesis of stationary against the alternative of a unit root. J Econom 54:159-178

Lane P, Milesi-Ferretti G-M (2001) The external wealth of nations: estimates of foreign assets and liabilities for industrial and developing countries. J Int Econ 55:263-294

Lane, P, Milesi-Ferretti G-M (2002) Long-term capital movements. NBER Macroeconomic Annual 16:73-116

Lane P, Milesi-Ferretti G-M (2004) The transfer problem revisited: net foreign assets and real exchange rates. Rev Econ Stat 86:841-857

Lewbel A (1992) Aggregation with log-linear models. Rev Econ Stud 59(3):635-642

Lütkepohl H, Krätzig M (2004) Applied time series econometrics. Cambridge University Press, Cambridge

Mojon B, Peersman G (2003) A VAR description of the effects of monetary policy in the individual countries of the Euro area. In Angeloni I et al (Eds) Monetary transmission in the Euro area, Chapter 3. Cambridge University Press, Cambridge

Ohlin B (1929) The reparation problem: a discussion. Econ J XXXIX:172-182

Pagan A (2003) An examination of some tools for macro-econometric model building, Mimeo, Rep. Natl. Soc Sci Surv

Peersman G, Smets F (2003) The monetary transmission mechanism in the Euro area: evidence from VAR analysis. In: Angeloni I et al (Eds) Monetary transmission in the Euro area, Chapter 2. Cambridge University Press, Cambridge

Pesaran HM, Shin Y (1996) Co-integration and speed of convergence to equilibrium. J Econom 71:117-143

Pesaran HM, Shin Y (1998) Generalized impulse response analysis in linear multivariate models. Econ Lett 58:17-29

Sarno L, Taylor MP (2002) Purchasing power parity and the real exchange rate. IMF Staff Papers 49:65-105

Selaive J, Tuesta V (2003a) Net foreign assets and imperfect pass-through: the consumption-real exchange rate anomaly. Board of Governors of the Federal Reserve System, International Finance discussion paper, 764

Selaive J, Tuesta V (2003b) Net foreign assets and imperfect financial integration: an empirical approach, Working paper 252. Central Bank of Chile, Chile 